\title{
Nanofibrillation of Dry Chitin Powder by Star Burst System
}

\author{
Shinsuke Ifuku, ${ }^{1}$ Kiyotaka Yamada, ${ }^{1}$ Minoru Morimoto, ${ }^{2}$ and Hiroyuki Saimoto ${ }^{1}$ \\ ${ }^{1}$ Department of Chemistry and Biotechnology, Graduate School of Engineering, Tottori University, 4-101 Koyama-cho Minami, \\ Tottori 680-8552, Japan \\ ${ }^{2}$ Research Center for Bioscience and Technology, Tottori University, 4-101 Koyama-cho Minami, Tottori 680-8550, Japan
}

Correspondence should be addressed to Shinsuke Ifuku, sifuku@chem.tottori-u.ac.jp

Received 4 January 2012; Revised 9 May 2012; Accepted 23 May 2012

Academic Editor: Tong Lin

Copyright () 2012 Shinsuke Ifuku et al. This is an open access article distributed under the Creative Commons Attribution License, which permits unrestricted use, distribution, and reproduction in any medium, provided the original work is properly cited.

Chitin nanofibers were prepared from dry chitin powder by nanofibrillation using a Star Burst instrument employing a highpressure water jet system. FE-SEM micrographs showed that the nanofibers became thinner as the number of Star Burst passes increased. Fibrillation in an acidic condition made the chitin fibers thinner than those in a neutral condition. The transmittance spectra of chitin nanofiber/acrylic resin composites led us to the same conclusion. In addition, chitin nanofibers prepared by treatment consisting of five Star Burst passes in the neutral condition were thinner than the previously reported nanofibers. X-ray diffraction profiles showed that the Star Burst system did not damage the chitin nanofibers and did not reduce their crystallinity.

\section{Introduction}

Chitin is the main component of the exoskeletons of arthropods such as crab and shrimp, as well as of the cell walls of fungi. It has a complex hierarchical organization consisting of chitin fibers, proteins, and minerals. These fibers were composed of fine nanofiber networks [1]. Chitin nanofibers are considered to have great potential, and various methods have been employed to prepare them [2$5]$. Recently, we have succeeded in isolating chitin nanofibers from the exoskeletons of crabs $[6,7]$ and prawns [8], and from the cell walls of mushrooms [9]. The nanofibers had a uniform structure, with widths of 10-20 nm and high aspect ratios (Figure 1). In those studies, a grinder (Masko Sangyo Co., Ltd.,) was used to atomize chitin to nanofibers. The complex organization of the chitin was broken down to nano size by the shearing forces generated by a specially designed pair of grinding stones. During this grinding treatment, an acidic condition is important in order to obtain chitin nanofibers. The electrostatic repulsion force between chitin nanofibers, which is caused by the cationization of amino groups, facilitates chitin atomization [10]. Although most chitin is thrown away as industrial waste, the nanofibers will open the door for potential applications as novel green nanomaterials.

Recently, a new atomizing system developed by Sugino Machine Co., Ltd., has attracted much attention for the production of biopolymer-based nanofibers $[11,12]$. The novel system, called Star Burst, applies high-pressure water jet technology for the wet disintegration of several samples. Compared to a grinder, the advantages of the Star Burst system are as follows. (1) The chitin slurry throughput amount can be easily arranged to a large extent from 2 to $840 \mathrm{l} / \mathrm{h}$ by changing the scale of the Star Burst equipment from small to large. (2) In principle, the system can produce the same nanofibers independent of the scale of the equipment, as long as the pressure with which a sample is ejected from the nozzle is constant. (3) This process introduces less contamination than the grinding process does.

If the Star Burst system efficiently yields chitin nanofibers, it will be a strong candidate for use in the mass production of chitin nanofibers. For this purpose, we expect that treatment under an acidic condition could be a key factor. Accordingly, we have studied the fibrillation of chitin into nanofibers by the Star Burst system under neutral and acidic conditions and characterized them in detail. 


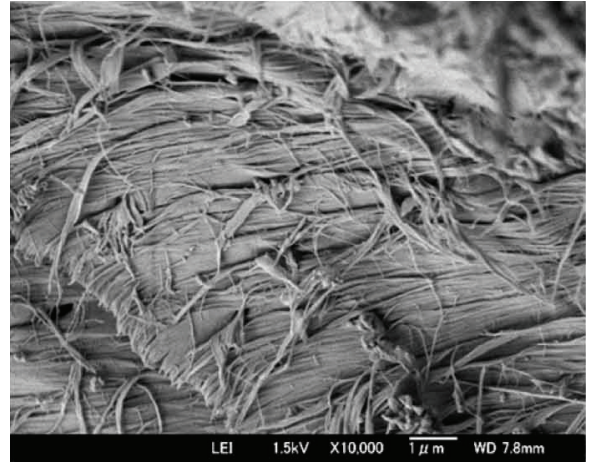

$1000 \mathrm{~nm}$

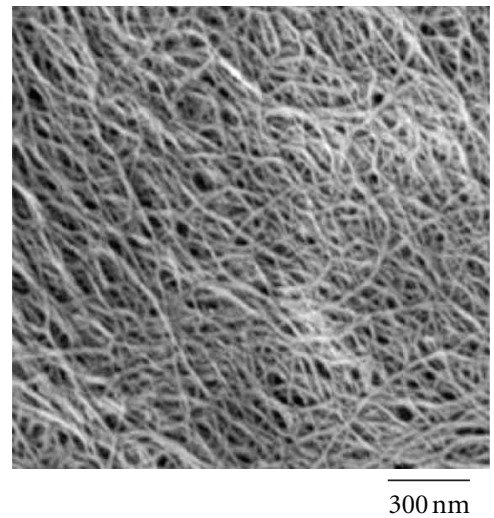

(b)

FIGURE 1: FE-SEM micrographs of (a) original chitin powder and (b) chitin nanofibers fibrillated by grinder under acidic condition.

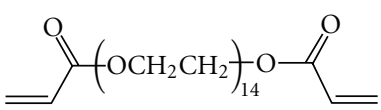

A- 600

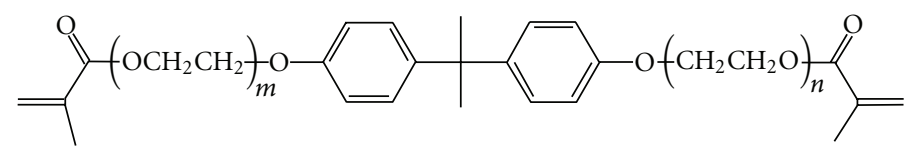

BPE-100 $(m+n=2.6)$

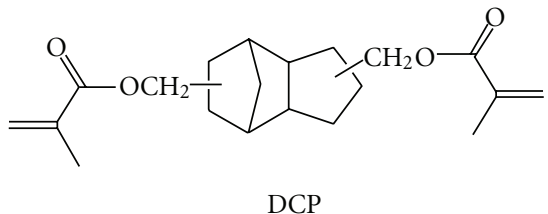

FIgURE 2: Chemical structures of acrylic monomers: A-600, BPE-100, and DCP.

\section{Experimental Sections}

2.1. Materials. $\alpha$-Chitin powder from crab shell and acetic acid were purchased from Nakalai Tesque and Kanto Reagent, respectively, and were used as received. Three types of acrylic monomers, tricyclodecane dimethanol dimethacrylate (DCP), poly(propylene glycol) diacrylate (A-600), and 2,2-bis[4-(methacryloxy polyethoxy)phenyl]propane (BPE100) were obtained from the Shin-Nakamura Chemical Co., Ltd., (see Figure 2).

2.2. Preparation of Chitin Nanofibers. Dry chitin powder was dispersed in water at $1 \mathrm{wt} . \%$. Acetic acid was added to adjust the $\mathrm{pH}$ value to 3 . The chitin was crushed roughly with a domestic blender. The slurry was stirred for $1 \mathrm{~h}$ under vacuum to remove air bubbles. The slurry was passed through the Star Burst system (Star Burst Mini, HJP-25001S, Sugino Machine Co., Ltd.,) equipped with a ball-collision chamber (Figure 3). The slurry was ejected from a small nozzle with a diameter of $100 \mu \mathrm{m}$ under high pressure
(245 MPa) and collided with ceramic ball with a diameter of $12.7 \mathrm{~mm}$. The suspension was passed 1,5 , and 10 times. Chitin nanofibers without acetic acid were also prepared by same procedure except for mechanical treatment under neutral condition.

2.3. Preparation of Chitin Nanofiber Composites. Fibrillated chitin nanofibers were dispersed in water at a fiber content of $0.1 \mathrm{wt} . \%$. The suspension was vacuum filtered using a membrane filter. The obtained chitin nanofiber sheets were dried by hot pressing at $100^{\circ} \mathrm{C}$ for $30 \mathrm{~min}$. The dried sheets were cut into $2 \mathrm{~cm} \times 2 \mathrm{~cm}$ squares of approximately $44 \mu \mathrm{m}$ thickness and with a weight of $12 \mathrm{mg}$. The squares were impregnated with bifunctional acrylic resins with $2 \mathrm{wt} . \%$ of 2-hydroxy-2-methylpropiophenone photoinitiator under a reduced pressure for $24 \mathrm{~h}$. The resin-impregnated sheets were radically polymerized using UV curing equipment (Spot Cure SP-7, Ushio Inc.) for $8 \mathrm{~min}$ at $40 \mathrm{mWcm}^{-1}$. The chitin nanofiber composite films thus obtained were approximately $64 \mu \mathrm{m}$ thick, and their fiber content was approximately $40 \%$, 


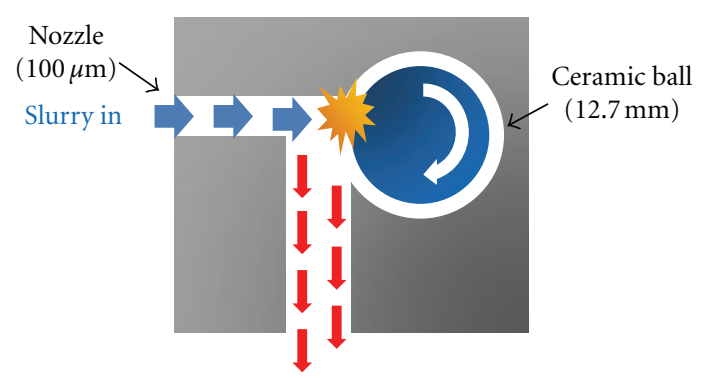

Out

Figure 3: Inner structure of ball-collision chamber of Star Burst system.

calculated based on the dry weights of the squares and nanocomposites. Neat acrylic resin films were also prepared under the same conditions.

2.4. Characterization. Infrared spectra of the samples were recorded with an FT-IR spectrophotometer (Spectrum 65, Perkin-Elmer Japan Co., Ltd.,) equipped with an ATR attachment. For field emission scanning electron microscope (FE-SEM) observation, the prepared nanofiber slurry was diluted with the EtOH and dried in an oven to prepare a chitin nanofiber sheet. The sample was coated with an approximately $2 \mathrm{~nm}$ layer of Pt by an ion sputter coater and observed by FE-SEM (JSM-6700F; JEOL, Ltd.,) operating at $2.0 \mathrm{kV}$. The average diameter of the isolated nanofibers was estimated by image analysis. X-ray diffraction profiles of the nanofibers were obtained with $\mathrm{Ni}$-filtered $\mathrm{CuK} \alpha$ from an X-ray generator (Ultima IV, Rigaku) operating at $40 \mathrm{kV}$ and $30 \mathrm{~mA}$. The diffraction profile was detected using an $\mathrm{X}$-ray goniometer scanning from $5^{\circ}$ to $35^{\circ}$. The crystalline index (CI) was determined by the following equation: $\mathrm{CI}=$ $\left(I_{110}-I_{\mathrm{am}}\right) \times 100 / I_{110}$, where $I_{110}$ is the maximum intensity of the 110 plane and $I_{\mathrm{am}}$ is the intensity of the amorphous diffraction at $16^{\circ}$ [13]. The light transmittances of chitin nanofibers/acrylic resin composite films were measured from 190 to $900 \mathrm{~nm}$ using a UV-vis spectrophotometer (V550; JASCO). Degrees of deacetylation of the chitin nanofibers were calculated from the $\mathrm{C}$ and $\mathrm{N}$ contents in the elemental analysis data by using elemental analyzer (Elementar Vario EL III, Elementar).

\section{Results and Discussion}

Star Burst is a water jet atomizing system with superhigh pressure. Chitin slurry was compressed by a hydraulic piston, ejected at high pressure (245 MPa) from a nozzle, and collide with ceramic ball in a chamber to atomize the chitin (Figure 3). The chitin powder with a concentration of $1 \mathrm{wt} \%$ was passed 1, 5, and 10 times through the Star Burst system under both neutral and acidic conditions. Figure 4 shows the appearances of chitin suspensions with $1 \mathrm{wt} . \%$ atomized by the Star Burst system. Generally, chitin does not disperse in water at all, which is known to be a big problem in its application. On the other hand, after the Star Burst

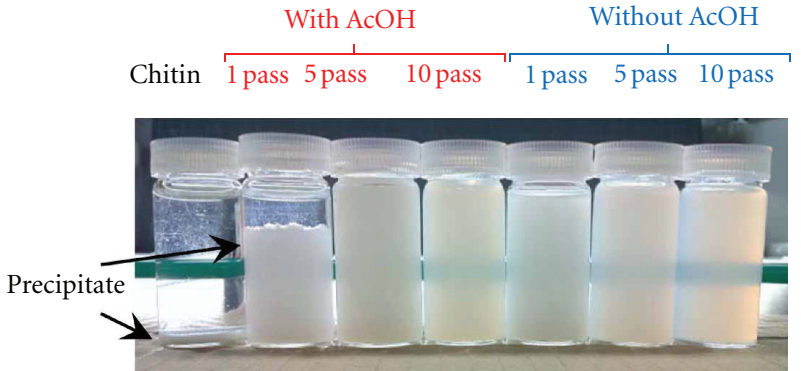

Figure 4: Appearances of chitin slurries treated by Star Burst system.

TABLE 1: Fiber thickness of fibrillated nanofibers with and without $\mathrm{AcOH}$ after various number of passes.

\begin{tabular}{lcc}
\hline \multirow{2}{*}{ Number of passes } & \multicolumn{2}{c}{ Fiber thickness (nm) } \\
& Without AcOH & With AcOH \\
\hline 1 & - & $19.0(4.9)$ \\
5 & $18.2(3.4)$ & $18.0(3.2)$ \\
10 & $17.3(3.2)$ & $16.5(3.3)$ \\
\hline
\end{tabular}

Standard deviations are given in parentheses.

treatment, chitin slurries dispersed well in water and did not precipitate for one month except for chitin treated one time without $\mathrm{AcOH}$. Compared with these appearances, the chitin slurry became more transparent as the number of treatments increased (compare the visibility of the green bar behind the slurries in Figure 4). This indicates that the Star Burst system successfully reduces chitin size, since transparency is strongly associated with chitin size.

Figure 5 shows FE-SEM micrographs of a chitin after Star Burst treatments under a neutral aqueous condition. After one pass, the chitin was not atomized at all (Figure 5(a)). Thick aggregates of chitin nanofibers were observed. This is because hydrogen bonding between the nanofibers is strong in dry chitin powder, thereby preventing nanofibrillation. On the other hand, there was a significant change in the morphology of the chitin after the treatment with five passes (Figures 5(b) and 5(c)). Most of the chitin aggregates were atomized well into tens-of-nanometers-scale fibers over an extensive area. These aggregates were similar to nanofibers atomized by a grinder [7]. They are made up of so-called chitin microfibril bundles. Thus, the atomization process is commonly called fibrillation. After 10 passes, the fiber width decreased further, apparently due to fibrillation of the thicker fibers (Figures 5(d) and 5(e)). Indeed, the average widths of the nanofibers fibrillated with 5 and 10 passes were 18.2 and $17.3 \mathrm{~nm}$, respectively, (Table 1).

Next, the chitin powder in water was passed through the Star Burst system under an acidic condition with $\mathrm{AcOH}$. Even after only one pass, chitin seems considerably fibrillated (Figures 6(a) and 6(b)) in comparison to the one-pass treatment under the neutral condition. Networks with nanosized and submicron fibers were observed. The remarkable difference between the results obtained with and without $\mathrm{AcOH}$ is obviously due to the repulsive force between the nanofibers. 


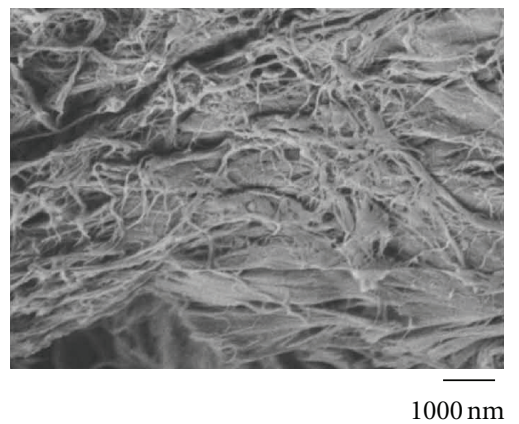

(a)

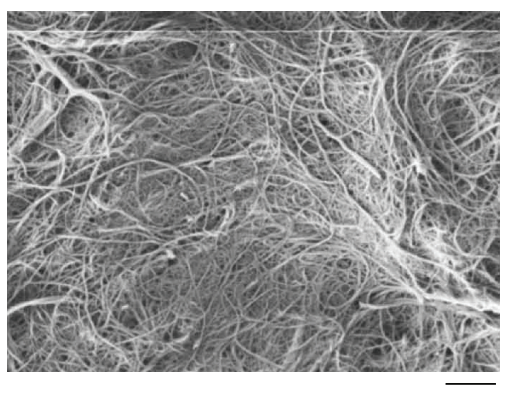

(b)

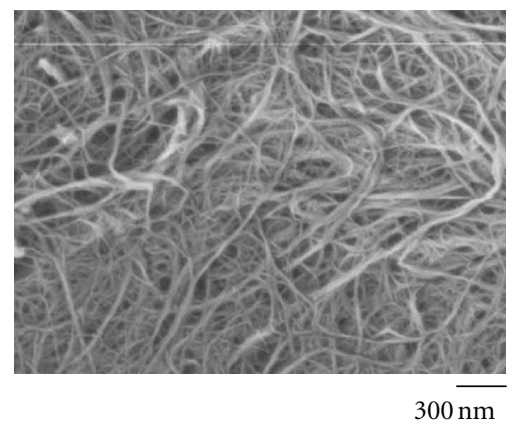

(c)

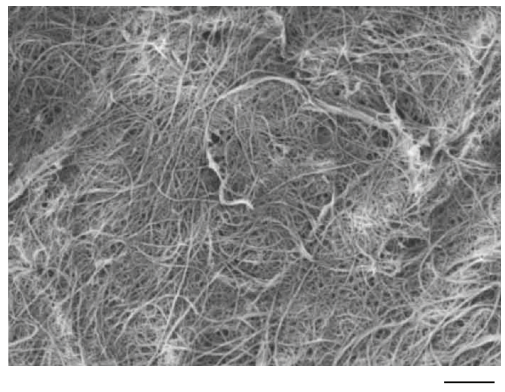

$1000 \mathrm{~nm}$

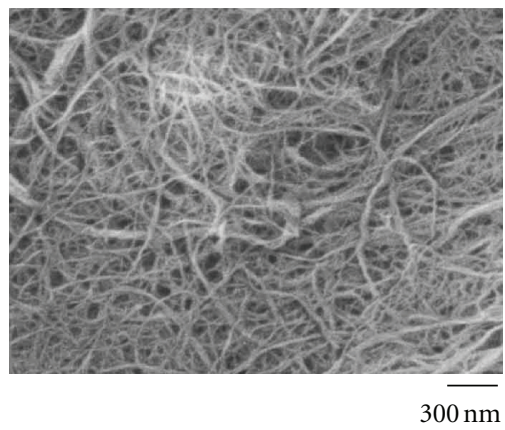

(e)

FIGURE 5: FE-SEM micrographs of chitin fibers with (a) 1 pass, ((b) and (c)) 5 passes, and ((d) and (e)) 10 passes through Star Burst system without acetic acid. The scale bar lengths are ((a), (b), and (d)) $1000 \mathrm{~nm}$ and ((c) and (e)) $300 \mathrm{~nm}$.

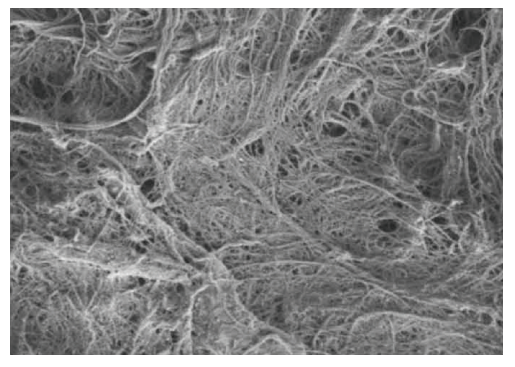

$100 \overline{\mathrm{nm}}$

(a)

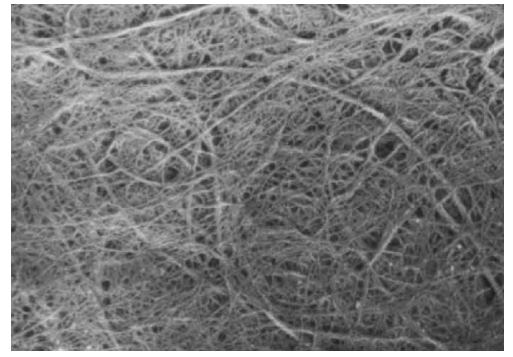

$300 \overline{\mathrm{nm}}$

(d)

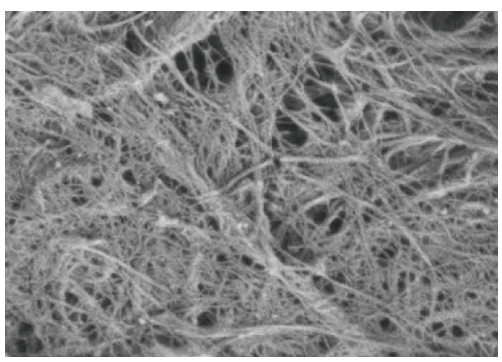

$30 \overline{0 \mathrm{~nm}}$

(b)

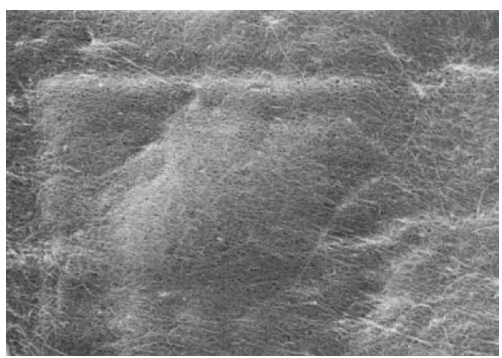

$100 \overline{\mathrm{nm}}$

(e)

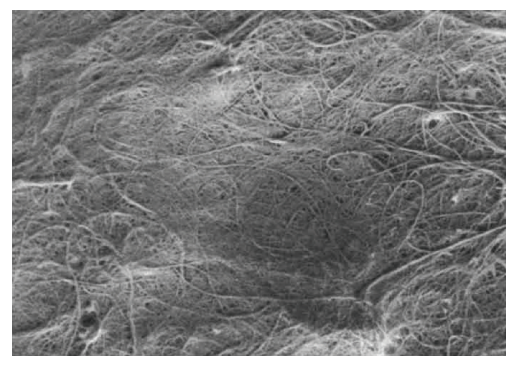

$100 \overline{\mathrm{nm}}$

(c)

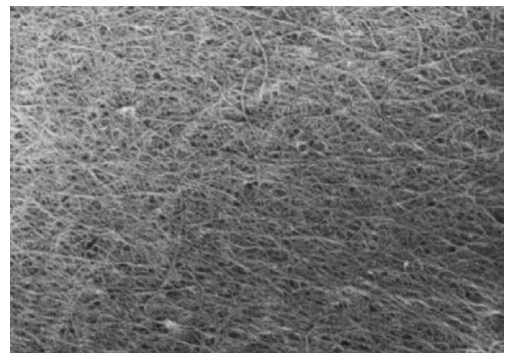

$30 \overline{0 \mathrm{~nm}}$

(f)

Figure 6: FE-SEM micrographs of chitin fibers after ((a) and (b)) 1 pass, ((c) and (d)) 5 passes, and ((e) and (f)) 10 passes through Star Burst system with acetic acid. The scale bar lengths are ((a), (c), and (e)) $1000 \mathrm{~nm}$ and ((b), (e), and (f)) $300 \mathrm{~nm}$. 


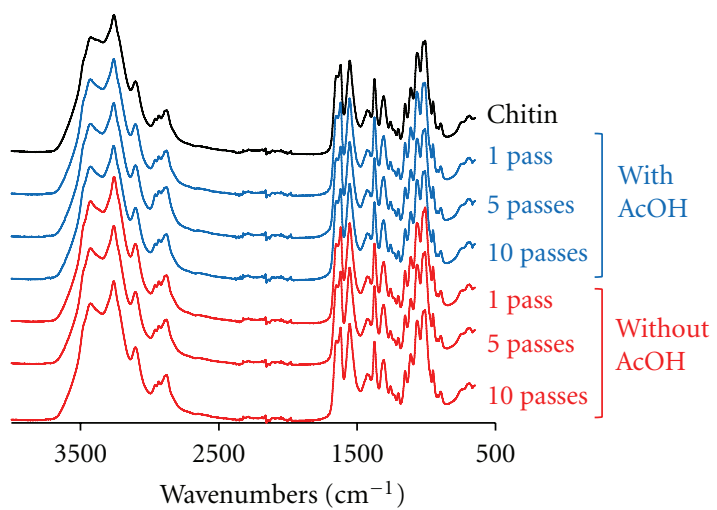

FIgURE 7: FT-IR spectra of chitin fibers after 1, 5, and 10 passes through Star Burst with and without acetic acid.

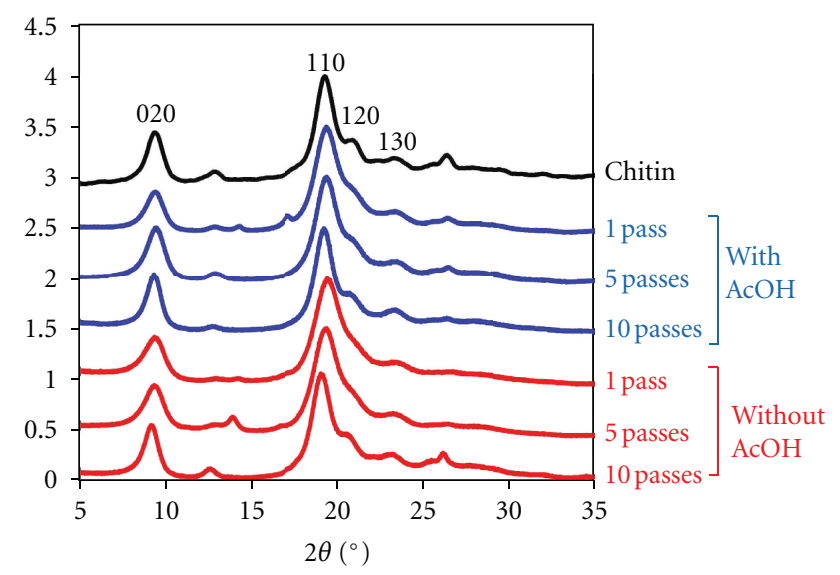

FIGURE 8: X-ray diffraction profiles of chitin fibers after 1, 5, and 10 passes through Star Burst with and without acetic acid.

Commercial chitin powder and obtained nanofibers have a small portion of amino groups at the $\mathrm{C} 2$ position with approximately $5 \%$ degree of deacetylation, which was caused by aqueous $\mathrm{NaOH}$ treatment to remove proteins from crab shell. Amino groups on the chitin fiber surface were cationized under an acidic condition, which allowed effective fibrillation by electrostatic repulsion. After five passes, the chitin fibers were further fibrillated. However, thicker fibers with widths of about $100 \mathrm{~nm}$, which were bundles of nanofibers, still remained in small numbers (Figures 6(c) and 6(d)). After 10 passes, the chitin was completely fibrillated and had a very fine nanofiber network (Figures 6(e) and 6(f)). The morphology was highly uniform, with a high-aspect ratio. Over a wide area, thicker fibers of about $100 \mathrm{~nm}$ diameter were not observed at all. Thus, the Star Burst treatment under both neutral and acidic conditions yielded fine chitin nanofibers.

Table 1 shows the average thicknesses of chitin nanofibers fibrillated with and without acetic acid. The thicknesses were estimated from FE-SEM images of nanofibers including a platinum-coating layer approximately $2 \mathrm{~nm}$ thick. It was difficult to estimate the thickness after one pass under neutral condition without acetic acid, since the chitin was not fully fibrillated. As the number of passes increased to 5 and then
TABLE 2: Relative degree of chitin nanofiber crystallinity prepared with and without $\mathrm{AcOH}$ at various numbers of passes.

\begin{tabular}{lcc}
\hline \multirow{2}{*}{ Number of passes } & \multicolumn{3}{c}{ Relative crystallinity (\%) } \\
& Without AcOH & With AcOH \\
\hline Original chitin & 83.7 \\
1 pass & 84.7 & 84.0 \\
5 pass & 85.2 & 84.0 \\
10 pass & 85.4 & 83.7 \\
\hline
\end{tabular}

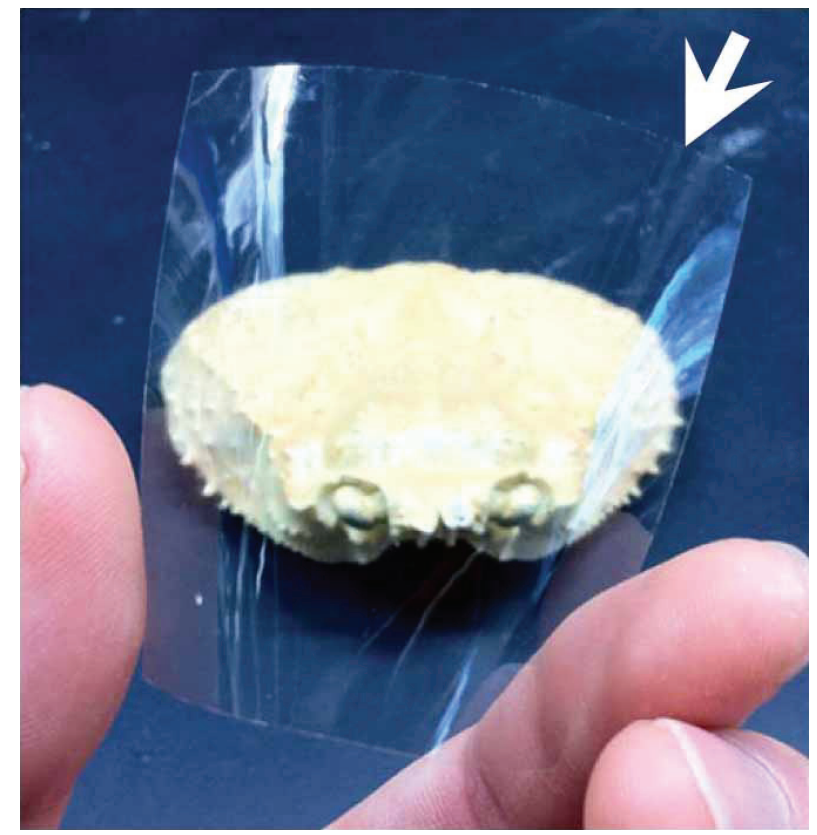

FIGURE 9: The appearance of transparent chitin nanofiber composite film.

to 10 , the nanofibers became thinner. In addition, the acidic condition improved the fibrillation of chitin, resulting in thinner nanofibers with fewer pass times.

Figure 7 shows the FT-IR spectra of chitin fibers treated by the Star Burst system after 1, 5, and 10 passes under both neutral and acidic conditions. All spectra of obtained chitin nanofibers are in excellent agreement with the spectrum of commercial chitin. In particular, the $\mathrm{OH}$ stretching band at $3424 \mathrm{~cm}^{-1}$, NH stretching band at $3259 \mathrm{~cm}^{-1}$, amide band I at 1652 and $1621 \mathrm{~cm}^{-1}$, and amide II band at $1554 \mathrm{~cm}^{-1}$ of the chitin nanofibers are observed. These absorption peaks are especially characteristic of chitin. This suggests that original chemical structures of chitin were maintained after Star Burst mechanical treatments.

Figure 8 shows the X-ray diffraction profiles of fibrillated chitin fibers by the Star Burst system after several passes under both neutral and acidic conditions. All diffraction patterns coincide closely with original chitin powder. The four diffraction peaks of the chitin nanofibers observed at $2 \theta=9.2,19.1,20.9$, and $23.1^{\circ}$ corresponded to 020,110 , 120 , and 130 planes, respectively, [14]. They were typical antiparallel crystal patterns of $\alpha$-chitin. Thus, the original crystalline structure was maintained after the purification 


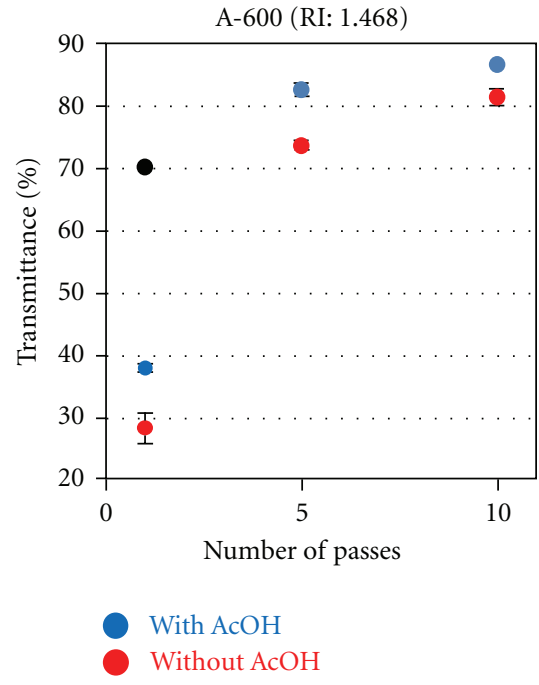

(a)

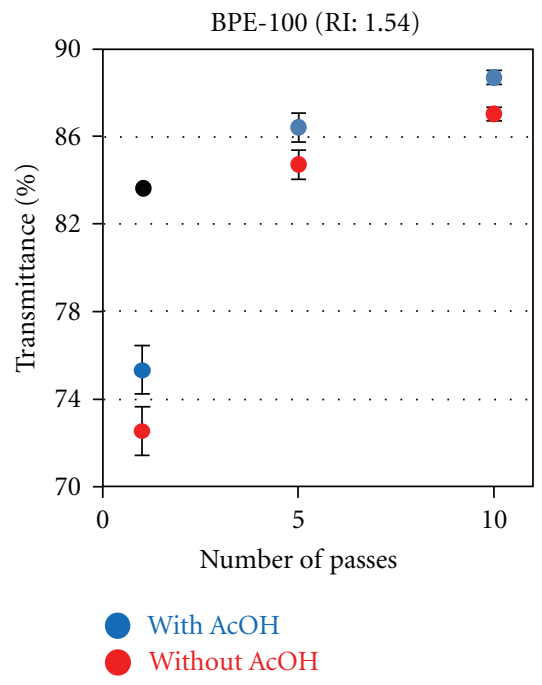

(b)

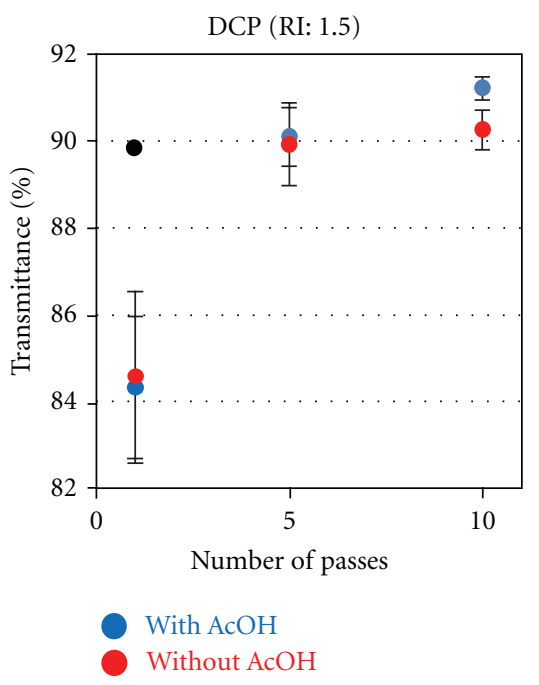

(c)

FIGURE 10: Regular light transmittances of acrylic resins ((a) A-600, (b) BPE-100, and (c) DCP) reinforced with chitin nanofiber with 1, 5, and 10 passes through Star Burst with (blue dots) and without acetic acid (red dots). Error bars show standard deviations. Black dots show transmittance of acrylic resins reinforced with chitin nanofibers with a previously reported procedure (one pass through a grinder with acetic acid).

process followed by the Star Burst treatments. Table 2 lists the relative crystalline indices of chitin nanofibers determined from X-ray diffraction profiles. Original chitin powder has a comparatively high crystallinity of $83.7 \%$. After the Star Burst process under both acidic and neutral conditions, there were no significant differences in the relative degree of crystallinity after the various numbers of passes. This result indicates that at least 10 mechanical treatments with the Star Burst system did not damage the chitin fibrils, even though the system used a super-high-pressure water jet of $245 \mathrm{MPa}$.

Since the FE-SEM images focused on small parts of the fiber networks, they cannot represent the total morphology of nanofibers. Recently, cellulose nanofiber-reinforced plastic films were reported [15]. Due to the nanofiber size effect, the nanocomposite was optically transparent even with a highfiber content. We have reported that the study is applicable to chitin nanofibers to obtain transparent nanocomposites [16]. Since the transparency depends strongly on fiber thickness and homogeneity, it can be used to quantify the relative macroscopic morphology of the nanofibers. Here, we prepared optically transparent nanocomposites using fibrillated chitin fibers with three different types of acrylic resins (Figure 9).

Figure 10 shows the regular light transmittances at $600 \mathrm{~nm}$ of acrylic resin films reinforced with chitin nanofibers. The refractive indices (RI) of three neat resins A-600, DCP, and BPE-100 were $1.468,1.500$, and 1.540 , and their light transmittances were approximately $90 \%$ at $600 \mathrm{~nm}$. In a previous study, it was known that the RI of DCP is the closest to chitin nanofiber, followed by BPE-100 and A-600, since the RI of resin to obtain a more transparent nanocomposite is in the range of approximately 1.49-1.53 [16]. The transparency of the nanocomposites indicates that
(1) nanofiber thickness decreased as the number of passes increased; (2) fibrillation under an acidic condition made chitin fibers thinner than under a neutral condition. These results agreed with the results of FE-SEM observation. Surprisingly, although chitin was not fibrillated at all after one-pass treatment under a neutral condition, the composite with DPC resin had a high transparency of $84.6 \%$ at $600 \mathrm{~nm}$. This indicates that, when the RIs between chitin and the matrix were strictly matched, the composite could be transparent even if the chitin fibers were not nanoscale [17]. This finding is helpful for developing an efficient preparation method for optically transparent bio-based composites.

In a previous study, we reported that chitin nanofibers were prepared by one pass through a grinder in aqueous $\mathrm{AcOH}$ and were complexed with acrylic resins [7]. The regular light transmittances of these nanocomposites with A600, BPE-100, and DCP resins were 72.1, 83.6, and 89.9\%, respectively. Compared with these transmittance data, chitin nanofibers with one-pass grinder treatment with $\mathrm{AcOH}$ were thinner than those with one-pass Star Burst treatment with and without $\mathrm{AcOH}$, but were thicker than those with five-pass Star Burst treatment without $\mathrm{AcOH}$, since the transmittances of their nanocomposites were 73.7 (A-600), 84.7 (BPE-100), and 89.9\% (DCP) (Figure 10).

\section{Conclusion}

We studied the fibrillation of dry chitin powder into nanofibers using the Star Burst system. FE-SEM micrographs of chitin nanofibers and light transmittances of the nanocomposites with acrylic resin showed that the morphology of chitin nanofibers depended strongly on the number of passes through the Star Burst system. The results also showed that 
treatment under an acidic condition was a key factor in chitin fibrillation into nanofibers effectively. X-ray diffraction profiles of the chitin nanofibers showed that the Star Burst treatment did not reduce their crystallinities, even though the Star Burst system uses a super-high-pressure water jet. The Star Burst system has advantages in quality stability, high-volume production, and low contamination. I expect that this unique system can play a strong role in the commercial use of chitin nanofibers.

\section{Acknowledgment}

This work was financially supported partially by KAKENHI (23750256) of JSPS.

\section{References}

[1] D. Raabe, C. Sachs, and P. Romano, "The crustacean exoskeleton as an example of a structurally and mechanically graded biological nanocomposite material," Acta Materialia, vol. 53, no. 15, pp. 4281-4292, 2005.

[2] J. F. Revol and R. H. Marchessault, "In vitro chiral nematic ordering of chitin crystallites," International Journal of Biological Macromolecules, vol. 15, no. 6, pp. 329-335, 1993.

[3] B. M. Min, S. W. Lee, J. N. Lim et al., "Chitin and chitosan nanofibers: electrospinning of chitin and deacetylation of chitin nanofibers," Polymer, vol. 45, no. 21, pp. 7137-7142, 2004.

[4] H. P. Zhao, X. Q. Feng, and H. Gao, "Ultrasonic technique for extracting nanofibers from nature materials," Applied Physics Letters, vol. 90, no. 7, Article ID 073112, 2007.

[5] Y. Fan, T. Saito, and A. Isogai, "TEMPO-mediated oxidation of $\beta$-chitin to prepare individual nanofibrils," Carbohydrate Polymers, vol. 77, no. 4, pp. 832-838, 2009.

[6] S. Ifuku, M. Nogi, K. Abe et al., "Preparation of chitin nanofibers with a uniform width as $\alpha$-chitin from crab shells," Biomacromolecules, vol. 10, no. 6, pp. 1584-1588, 2009.

[7] S. Ifuku, M. Nogi, M. Yoshioka, M. Morimoto, H. Yano, and H. Saimoto, "Fibrillation of dried chitin into 10$20 \mathrm{~nm}$ nanofibers by a simple grinding method under acidic conditions," Carbohydrate Polymers, vol. 81, no. 1, pp. 134$139,2010$.

[8] S. Ifuku, M. Nogi, K. Abe et al., "Simple preparation method of chitin nanofibers with a uniform width of 10-20 nm from prawn shell under neutral conditions," Carbohydrate Polymers, vol. 84, no. 2, pp. 762-764, 2011.

[9] S. Ifuku, R. Nomura, M. Morimoto, and H. Saimoto, "Preparation of chitin nanofibers from mushrooms," Materials, vol. 4, no. 8, pp. 1417-1425, 2011.

[10] Y. Fan, T. Saito, and A. Isogai, "Preparation of chitin nanofibers from squid Pen $\beta$-chitin by simple mechanical treatment under acid conditions," Biomacromolecules, vol. 9, no. 7, pp. 1919-1923, 2008.

[11] R. Kose and T. Kondo, "Favorable 3D-network formation of chitin nanofibers dispersed in water prepared using aqueous counter collision," Sen-I GakkaIshI, vol. 67, no. 4, pp. 91-95, 2011.

[12] Y. Watanabe, S. Kitamura, K. Kawasaki et al., "Application of a water jet system to the pretreatment of cellulose," Biopolymers, vol. 95, no. 12, pp. 833-839, 2011.

[13] Y. Zhang, C. Xue, Y. Xue, R. Gao, and X. Zhang, "Determination of the degree of deacetylation of chitin and chitosan by
X-ray powder diffraction," Carbohydrate Research, vol. 340, no. 11, pp. 1914-1917, 2005.

[14] R. Minke and J. Blackwell, "The structure of $\alpha$-chitin,” Journal of Molecular Biology, vol. 120, no. 2, pp. 167-181, 1978.

[15] H. Yano, J. Sugiyama, A. N. Nakagaito et al., "Optically transparent composites reinforced with networks of bacterial nanofibers," Advanced Materials, vol. 17, no. 2, pp. 153-155, 2005.

[16] S. Ifuku, S. Morooka, A. Norio Nakagaito, M. Morimoto, and H. Saimoto, "Preparation and characterization of optically transparent chitin nanofiber/(meth)acrylic resin composites," Green Chemistry, vol. 13, no. 7, pp. 1708-1711, 2011.

[17] I. Shams, M. Nogi, L. A. Berglund, and H. Yano, “The transparent crab: preparation and nanostructural implications for bioinspired optically transparent nanocomposites," Soft Matter, vol. 8, pp. 1369-1373, 2012. 

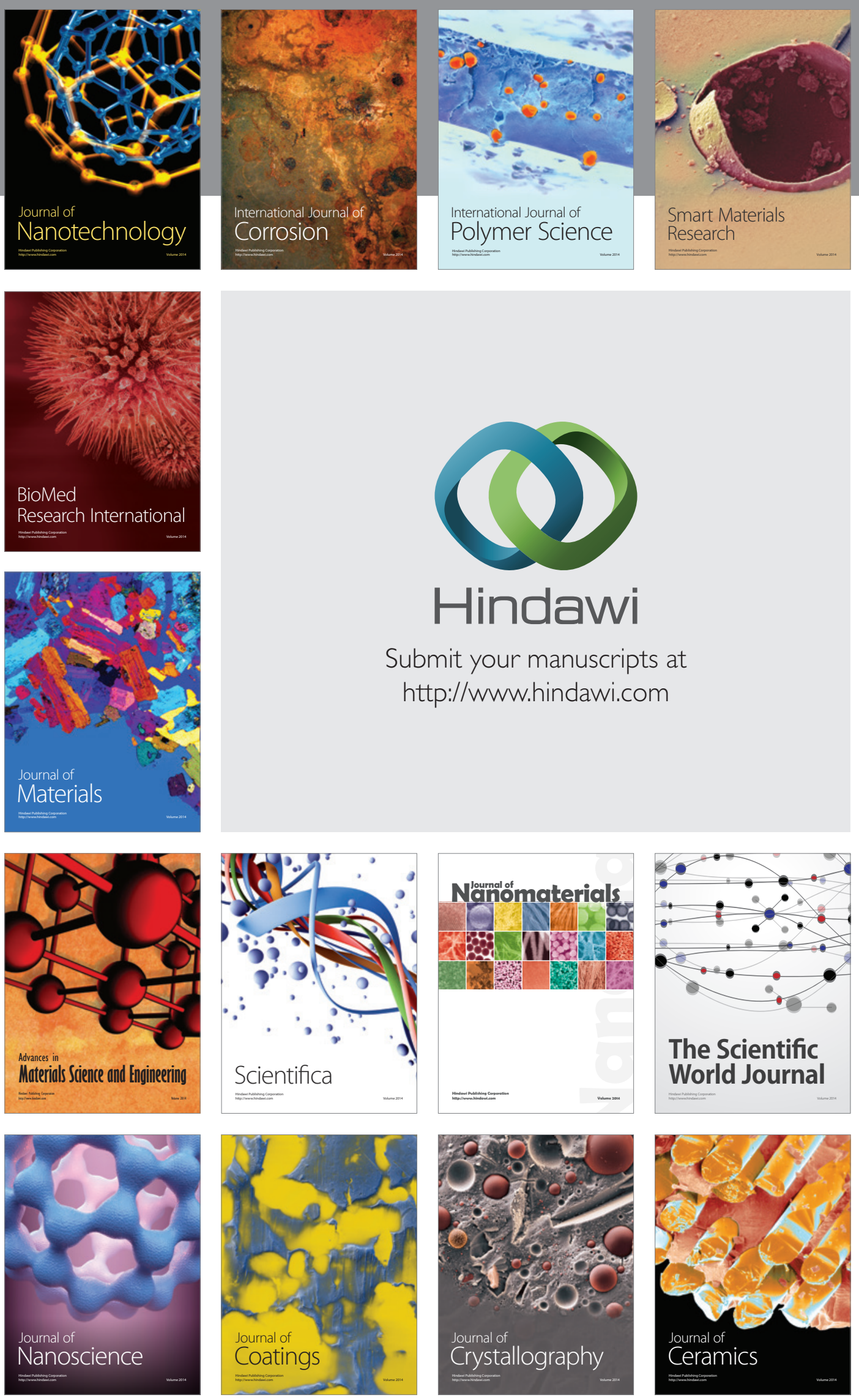

The Scientific World Journal

Submit your manuscripts at

http://www.hindawi.com

\section{World Journal}

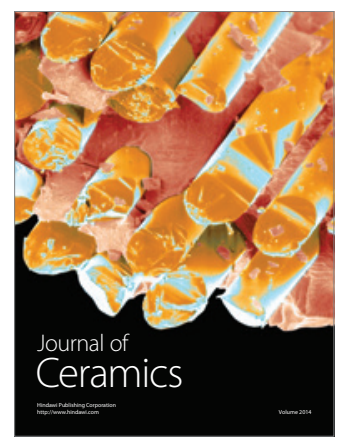

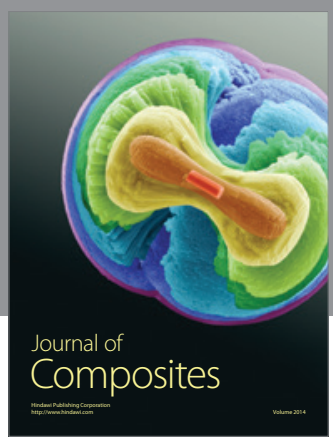
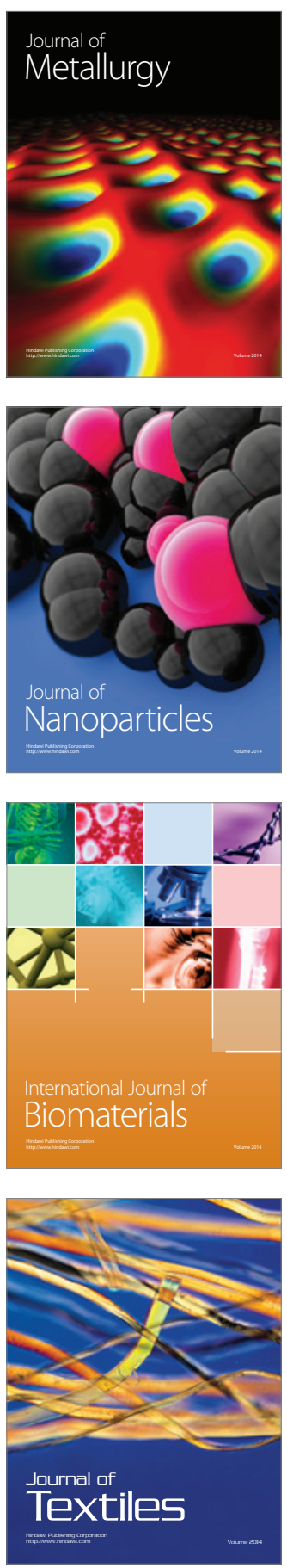